\title{
Philippe Rocher, Le goût de l'excellence. Quatre siècles d'éducation jésuite en France
}

Paris, Beauchesne, coll. « Bibliothèque Beauchesne, no 38 ", 2011, 438 p.

\section{Pascale Gruson}

\section{(Q) OpenEdition}

\section{Journals}

Édition électronique

URL : http://journals.openedition.org/assr/24707

DOI : $10.4000 /$ assr. 24707

ISSN : $1777-5825$

Éditeur

Éditions de l'EHESS

Édition imprimée

Date de publication : 30 décembre 2012

Pagination : 267

ISSN : 0335-5985

Référence électronique

Pascale Gruson, «Philippe Rocher, Le goût de l'excellence. Quatre siècles d'éducation jésuite en France », Archives de sciences sociales des religions [En ligne], 160 | octobre-décembre 2012, mis en ligne le 29 mars 2013, consulté le 21 septembre 2020. URL : http://journals.openedition.org/assr/ 24707 ; DOI : https://doi.org/10.4000/assr.24707

Ce document a été généré automatiquement le 21 septembre 2020.

(c) Archives de sciences sociales des religions 


\section{Philippe Rocher, Le goût de l'excellence. Quatre siècles d'éducation jésuite en France}

Paris, Beauchesne, coll. « Bibliothèque Beauchesne, no 38 », 2011, 438 p.

\section{Pascale Gruson}

\section{RÉFÉRENCE}

Philippe Rocher, Le goût de l'excellence. Quatre siècles d'éducation jésuite en France, Paris, Beauchesne, coll. « Bibliothèque Beauchesne, no 38 ", 2011, 438 p. 
$1 \quad$ Il existe déjà de nombreux travaux sur les jésuites, parmi lesquels beaucoup se concentrent plus particulièrement sur la mission éducative de la Compagnie, inscrite par Ignace de Loyola dans les «Constitutions ». Philippe Rocher n'en a pas été découragé et son livre trouve sûrement une place originale dans ce catalogue, puisqu'il se propose de suivre, sans indulgence et, selon lui, en objectivité, les tours et détours de cet apostolat en France, pendant les quatre siècles qui séparent la fondation, à Billom, du premier collège, de notre présent.

2 Il fallait bien sûr commencer pas le commencement, soit la vie du fondateur, Ignace (Ignido avant sa vocation) de Loyola, son éducation, ses premiers compagnons, l'installation à Montmartre, l'obédience directe au Pape, les

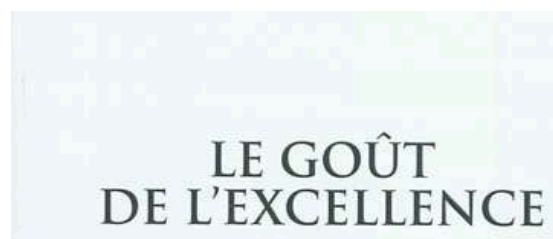

Quatre siècles d'éducation jésuite en France par PHILIPPE ROCHER

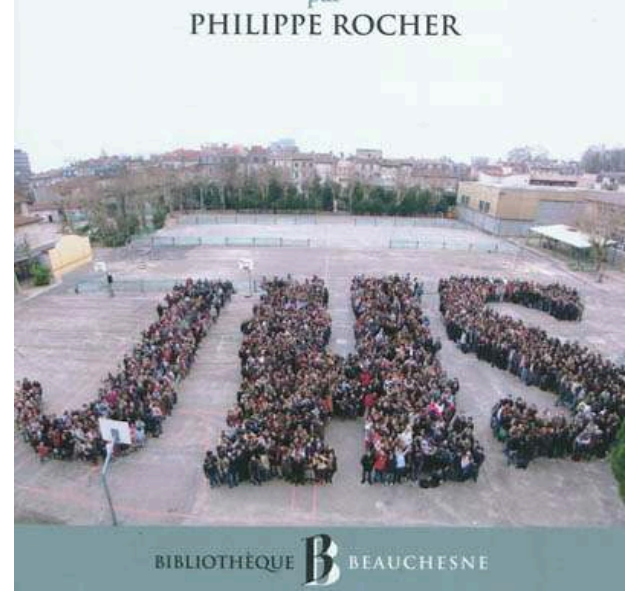
«Constitutions », donc l'engagement dans une mission éducative auprès des élites dont le Ratio studiorum est l'armature essentielle. Le Ratio studiorum est un programme pédagogique fondé sur l'enseignement des humanités, grec et latin, qui, selon l'auteur, ne laisse que peu de place aux mathématiques ou aux sciences, et n'en fait aucune à un enseignement pratique et professionnel. Mais au XVI ${ }^{\mathrm{e}}$ siècle, posait-on ce problème en ces termes? Ce n'est en tout cas qu'au $\mathrm{XVIII}^{\mathrm{e}}$ siècle que des établissements d'enseignement technique commencent à voir le jour, et ce, plutôt en Allemagne. Le projet impose aux élèves de vivre en internat, les professeurs se substituant ainsi aux familles pour compléter l'apprentissage des règles de civilité et de bonne conduite. La pratique du théâtre occupe assez vite une place importante dans l'emploi du temps.

3 Grâce aux collèges, Ignace de Loyola pensait bien sûr d'abord se donner les moyens de former de nouveaux jésuites. Mais il n'a jamais exclu de donner une éducation d'honnête homme à une élite appelée à des responsabilités politiques.

4 Le premier des collèges voit donc le jour en France, en 1554, à Billom, rapidement suivi, en 1564 d'un collège à Paris, puis de beaucoup d'autres sur l'ensemble du territoire.

5 Très vite, l'éducation jésuite connaît le succès et, très vite, son excellence supposée, affirmée, est l'objet de débats : par exemple, Colbert, qui a confié son fils à l'un de ces établissements, se plaint d'une formation peu ouverte tant à la science qu'à ses applications. Les critiques se multiplient au temps de la Philosophie des Lumières pour se taire provisoirement en 1762, lorsque le Parlement décide de chasser la Compagnie hors de France. En 1664, on le sait, Rome condamne la Compagnie et prononce sa dissolution.

Lorsque les jésuites reviennent en "grâce romaine ", en 1814, les paysages éducatifs nationaux dans lesquels ils étaient intervenus, la France tout particulièrement, se sont modifiés. Il y a maintenant, en France, des Écoles spéciales, chargées de donner une 
éducation scientifique exigeante à ceux qui pourront alors appartenir aux grands corps de l'État; il y a des lycées d'État qui préparent les élèves méritants (et pauvres) à entrer dans ces écoles d'enseignement supérieur. L'enseignement jésuite doit s'adapter à ce nouveau paysage, mais il ne paraît pas particulièrement performant : le Ratio studiorum ne fait guère plus de place qu'avant à l'enseignement scientifique; les collèges n'ont pas acquis de compétences équivalentes à celles des établissements d'enseignement supérieur moderne qui ont vu peu à peu le jour au XIXe siècle. Au début de la $\mathrm{III}^{\mathrm{e}}$ République, le "déphasage " s'accentue, dans un contexte difficile de laïcité militante et de crise moderniste. La Compagnie décide alors de diversifier son apostolat auprès de la jeunesse. De la création de l'Association catholique de la jeunesse française (ACJF), à la fin du XIX ${ }^{e}$ siècle, jusqu'à celle du Chemin neuf, le mouvement charismatique créé à Lyon à la fin du Xxe siècle, les expériences sont riches : le scoutisme, la JEC, la JOC, etc.

7 Les innovations les plus récentes suffiront-elles, se demande Philippe Rocher, à redonner à la Compagnie l'élan dont elle a besoin et à contrer son vieillissement ?

Il faut se demander en fait si la question a été bien posée, car si Philippe Rocher cherche à établir un bilan (assez désabusé) de la mission jésuite d'éducation, telle que fixée par son fondateur, il ne donne pas nécessairement au lecteur les moyens efficaces d'une appréciation équilibrée. On le sent par exemple immédiatement critique du Ratio studiorum supposé décalé de la vie active à laquelle il doit préparer. Mais ce jugement global, s'il est avéré, ce qui est loin d'être clair, ne peut s'appliquer qu'à notre actualité (ce n'est que depuis peu de temps, après 1945, que beaucoup reprochent au système d'enseignement (en l'occurrence public) de ne pas avoir le souci d'une formation professionnelle et d'être trop abstrait. L'anachronisme n'est pas vraiment maîtrisé.

Plus généralement, dans la critique du Ratio studiorum, la référence à une éducation qui pourrait être bonne n'est pas vraiment développée: peu de place est faite à cette exigence, telle que l'humanisme (Rabelais, Montaigne) l'a pensée dans sa diversité. Les conflits qui opposent la Réforme et la Contre-Réforme (jésuites, oratoriens, jansénistes, quiétistes, etc.) sur le thème de l'éducation ne sont pas pris en compte.

Par ailleurs, le cycle des études jésuites n'est évidemment pas aussi étroit que l'auteur ne le laisse plus d'une fois penser ; l'enseignement des mathématiques y a eu une place : sur ce point l'exemple de l'École navale de Brest créée au XVII siècle aurait mérité une analyse moins "partisane ». Les liens entre formation à l'abstraction, enseignement général et enseignement technique, la division des responsabilités qui s'y rapportent, auraient valu une exploration préalable plus attentive. Enfin, il faut rappeler que lorsque les jésuites ont été chassés de France, il a été bien difficile de trouver une structure d'enseignement qui présentait les mêmes avantages d'excellence. Et c'est d'ailleurs sur le modèle de l'éducation jésuite que les premiers lycées napoléoniens ont été créés.

11 Ces approximations tiennent peut-être au fait que devant l'abondance de la documentation, devant l'abondance des personnages impliqués, Philippe Rocher devait faire des choix. Que ceux-ci ne soient pas vraiment satisfaisants au regard du thème de l'éducation proprement dit, ne doit pas masquer des points très positifs, beaucoup d'informations intéressantes, une écriture plaisante, une présentation claire et aérée, ponctuée d'utiles récapitulatifs, des annexes bien choisies, y compris un texte peu connu de Gabriel Compayré sur l'éducation jésuite. 